\title{
AS POLÍTICAS EDUCACIONAIS E O NEOLIBERALISMO NA AMÉRICA LATINA E NO CARIBE: PRIMEIRAS APROXIMAÇÕES
}

Vinicius Renan Rigolin de Vicente ${ }^{1}$, Raquel Alessandra de Deus Silva², Jani Alves da Silva Moreira ${ }^{3}$

${ }^{1}$ Mestrando em Educação pela Universidade Estadual de Maringá (UEM). Pesquisador do Grupo de Estudos e Pesquisa em Políticas Educacionais, Financiamento e Gestão da Educação - GEPEFI/CNPq. Bolsista pela Coordenação de Aperfeiçoamento de Pessoal de Nível Superior (CAPES). E-mail: viniciusrigolin@hotmail.com

${ }^{2}$ Mestranda em Educação pela Universidade Estadual de Maringá (UEM). Pesquisadora do Grupo de Estudos e Pesquisa em Políticas Educacionais, Financiamento e Gestão da Educação - GEPEFI/CNPq. Bolsista pelo Conselho Nacional de Desenvolvimento Científico e Tecnológico (CNPq).

${ }^{3}$ Doutora e Mestre em Educação pela Universidade Estadual de Maringá. Professora Adjunta do Departamento de Teoria e Prática Educação e do Programa de Pós-Graduação em Educação. Líder do Grupo de estudos e pesquisa em políticas educacionais, financiamento e gestão da educação GEPEFI/CNPq.

\section{RESUMO}

O texto objetiva compreender o contexto de reforma educacional sob os auspícios do Neoliberalismo a fim de analisar o papel que o Projeto Principal de Educação para América Latina e Caribe (PPE) desempenhou na definição de diretrizes educacionais aos países. Discorre-se acerca da implementação das ideias e políticas neoliberais e como consolidam-se no campo educacional. Busca-se apresentar as propostas do PPE para a América Latina e o Caribe com o intuito de demonstrar a atuação e configuração do referido projeto. A metodologia adotada foi de uma pesquisa de análise documental, de cunho teórico bibliográfico. Questiona-se: As políticas educacionais propostas a partir dos anos de 1990, na América Latina e no Caribe seguiram as diretrizes do Neoliberalismo? Qual o papel do PPE no contexto da reforma educacional para esses países? Conclui-se que as políticas educacionais fundamentam-se nas mudanças concretizadas a partir da realidade histórica-concreta e que adotou proposições recomendadas pelo PPE.

Palavras-chave: Políticas Educacionais. Neoliberalismo. Educação. Projeto Principal para América Latina e Caribe. Organizações e Organismos Internacionais.

\section{EDUCATIONAL POLICIES AND NEOLIBERALISM IN LATIN AMERICA AND THE CARIBBEAN: FIRST APPROACHES}

\begin{abstract}
The text aims to understand the context of educational reform under the auspices of neoliberalism in order to analyze the role that the major project of education in Latin America and the Caribbean (Projeto Principal de Educação para América Latina e Caribe - PPE) has played in the definition of educational directives for countries. It expatiates about the implementation of neoliberal ideas and policies and how they are consolidated in the educational field. It seeks to present the proposals of the PPE for Latin America and the Caribbean with the purpose of demonstrating the performance and configuration of the abovementioned project. The methodology adopted was a research of documentary analysis, with a bibliographic theoretical framework. It is questioned: have the educational policies proposed since the 1990s in Latin America and the Caribbean followed the guidelines of neoliberalism? What is the role of the PPE in the context of the educational reform for these countries? It is concluded that the educational policies are based on the changes accomplished since the concrete historical reality and that it adopted propositions recommended by the PPE.
\end{abstract}

Keywords: Educational Policies. Neoliberalism. Education. Major Project of Education in Latin America and the Caribbean. International Organizations and Organisms. 


\section{INTRODUÇÃO}

O receituário da Doutrina Econômica Neoliberal foi implantado por diversos países nas décadas de 1970 e 1980, sobretudo em algumas nações da Europa e nos Estados Unidos. Com base capitalista, o neoliberalismo propaga um conjunto de ideias políticas e econômicas que defende a não participação do Estado na economia. Nas premissas da doutrina, os neoliberais argumentam que deve haver total liberdade do comércio para garantir o crescimento econômico e o desenvolvimento social de um país. As ideias neoliberais não afetaram somente o campo da economia, mas também influenciaram nos determinantes das reformas dos Estados e em mudanças nas diversas áreas sociais, dentre elas a educação.

No Brasil, na década de 1990, os princípios neoliberais impulsionaram a Reforma do Aparelho do Estado. Esta última consistiu na redefinição das funções do Estado e justificava-se pela necessidade de modernizá-lo, de seguir as mudanças da transnacionalização do capital, de racionalizar os recursos e buscar novas condições de financiamento, bem como de reorganizar o processo de produção.

A política e o sistema educacional no Brasil, sobretudo, a partir dos anos de 1990, passaram por diversas mudanças provenientes de reformas e reformulações na legislação, na estrutura e organização dos sistemas de ensino. Esse contexto de mudança seguiu recomendações de Organizações e Organismos Internacionais ${ }^{1}$, como a Organização das Nações Unidas (ONU), a Organização das Nações Unidas para a Educação, a Ciência e a Cultura (UNESCO), a Comissão Econômica para a América Latina e Caribe (CEPAL), a Organização para a Cooperação e Desenvolvimento Econômico (OCDE), o Banco Mundial (BM) entre outros.

Este artigo resulta de uma pesquisa de análise documental, desenvolvida no Mestrado em Educação no Programa de Pós-Graduação da Universidade Estadual de Maringá, no qual a proposta foi investigar o contexto de reforma

\footnotetext{
1 Apesar de não existir uma nomenclatura padrão entre os pesquisadores para referirem-se às Organizações Internacionais que atuam em âmbito global, visto que se pode encontrar diferentes denominações como Organizações Multilaterais (OMs), Organizações Intergovernamentais (Ols), Organizações Internacionais (OI), entre outros, optou-se por utilizar o nome de Organizações e Organismos Internacionais (OOs). A escolha justificase, pois, segundo Moreira (2015), o termo Organizações Internacionais contempla uma variedade de instituições diferentes em suas origens e funções.
}

educacional sob os auspícios do neoliberalismo. Para essa análise considerou-se a compreensão acerca do papel que o Projeto Principal de Educação para América Latina e Caribe (PPE) ${ }^{2}$ desempenhou na definição de diretrizes educacionais aos países. Para dar conta do proposto, discorre-se acerca da implementação das ideias e políticas neoliberais, e como estas são consolidadas no campo educacional. Desta maneira, busca-se apresentar as propostas do PPE para a América Latina e o Caribe, organizado pela UNESCO, com o intuito de demonstrar a atuação e configuração do referido projeto.

\section{METODOLOGIA}

Apresentam-se os resultados de uma pesquisa de análise documental, de cunho teórico bibliográfico. 0 objeto de estudo selecionado refere-se às políticas educacionais no contexto neoliberal, no qual se investiga qual o papel do Projeto Principal de Educação para América Latina e Caribe (PPE) na definição das diretrizes políticas para a educação, especificamente a partir da década de 1990. Nesse sentido, como problema de pesquisa questiona-se: As políticas educacionais propostas a partir dos anos de 1990, na América Latina e no Caribe seguiram as diretrizes da doutrina econômica neoliberal? Qual o papel do PPE no contexto da reforma educacional para esses países?

Tal mediação analítica foi estabelecida tendo como consideração que as políticas educacionais têm como base as mudanças concretizadas a partir da realidade históricoconcreta, portanto, parte-se da compreensão da totalidade histórica para, em seguida, compreender os mecanismos de definição das políticas educacionais no contexto de retomada dos princípios do (neo)liberalismo na educação.

\section{RESULTADOS E DISCUSSÃO}

Ao apresentar os resultados e discussões optou-se por expor, primeiramente, uma compreensão histórica sobre as facetas do neoliberalismo enquanto uma Doutrina Econômica. Em seguida, apreendem-se as implicações do neoliberalismo no campo educacional e as interferências de Organizações e Organismos Internacionais para, posteriormente, analisar as definições e recomendações do PPE

\footnotetext{
2 Criado no final dos anos 1970, na Conferência Regional de Ministros da Educação e Ministros Encarregados do Planejamento Econômico.
} 
na constituição das diretrizes políticas para a educação na América Latina e no Caribe.

\section{Contexto histórico e o Neoliberalismo}

Neste subitem buscou-se retomar alguns elementos do contexto histórico e compreender como se materializou o ideário neoliberal nas políticas de cunho econômico-social a partir do recorte histórico pós Segunda Guerra Mundial.

Após a Segunda Guerra Mundial, os países, como Estados Unidos e Inglaterra, viviam sob o regime de acumulação econômica chamado de liberalismo embutido, de Estado de Bem-Estar Social, de Welfare State ou de keynesiano, termo referente ao economista britânico John Maynard Keynes (1883-1946), por meio de sua obra Teoria geral do emprego, do juro e da moeda (1936). A doutrina keynesiana expandiu-se por diferentes nações do mundo e resultou em um capitalismo com toque de democracia, na tentativa de estabilizar e combinar as relações entre Estado e mercado (HARVEY, 2011; NETTO; BRAZ, 2012).

É nesse período que foram realizados tratados entre as nações como os acordos de Bretton Woods $(1944)^{3}$, com o intuito de estabelecer a paz e a tranquilidade econômica no pós-guerra e, especialmente, depois da crise de 1929. Além disso, neste mesmo contexto foram criadas várias Organizações e Organismos Internacionais como a Organização das Nações Unidas (ONU), o Banco Mundial (BM) e o Fundo Monetário Internacional (FMI), entre outros, para atuarem na reconstrução dos países devastados pela guerra e para contribuírem na harmonização das relações internacionais (HARVEY, 2011).

As políticas keynesianas baseavam-se na forte intervenção do Estado em diversos setores da sociedade com o fito de promover o bem estar dos cidadãos. Isso exigia a participação estatal na economia para evitar crises e garantir um nível satisfatório de emprego. Desse modo, a intervenção estatal regulava as atividades privadas ou mesmo as substituía por meio de investimento público (HARVEY, 2011).

Todavia, ao final da década de 1960 e início do decênio de 1970, este modelo de

\footnotetext{
${ }^{3}$ Em julho de 1944, na cidade de Bretton Woods, nos Estados Unidos, ocorreu a chamada Conferência de Bretton Woods, na qual foram reunidos representantes de 44 nações do mundo, entre elas o Brasil. Por intermédio dos acordos firmados nesta conferência, desenvolveu-se um sistema de normas para controlar a política econômica internacional, o que exigiu estabilidade monetária entre os países e criação de Organismos Internacionais que acompanhasse o sistema financeiro, o FMI e o BM são exemplos destes (BARRETO, 2009).
}

organização econômica enfrentou um período de crises. Considera-se que a crise é imanente ao modo de produção capitalista, "[...] é constitutiva do capitalismo: não existiu, não existe e não existirá capitalismo sem crise (NETTO; BRAZ, 2012, p. 170, grifos dos autores)". Embora o Estado de Bem-Estar Social, por meio de ações intervencionistas do Estado, controlasse as crises desenvolvidas com rápidas retomadas e tornasse a economia planificada, esse modelo esgotou-se.

As crises do modelo keynesiano referemse a queda das taxas de lucro, a redução do incremento econômico, ao crescente número de desempregados e a inflação acelerada. Outros acontecimentos intensificaram a situação: o colapso da taxa de câmbio, no ano de 1971, definida pelo acordo de Bretton Woods, que consistiu na desvinculação do dólar com o ouro, e o choque do petróleo com a alta de preços em 1973, estabelecida pela Organização dos Países Exportadores de Petróleo (OPEP) (NETTO; BRAZ, 2012). Harvey (2011, p. 22) confirma:

Os sinais de uma grave
crise de acumulação eram
em toda parte aparentes.
O desemprego e a inflação
se ampliavam em toda
parte, desencadeando
uma fase global de
"estagflação" que duraria
boa parte dos anos 1970.
Surgiram crises fiscais de
vários Estados [...]
enquanto receitas de
impostos caíram
acentuadamente e os
gastos sociais disparavam.
As políticas keynesianas já
não funcionavam.

A partir do momento em que o modelo keynesiano declinou, aproximadamente no início da década de 1970, o neoliberalismo ganhou espaço nas direções dos Estados nacionais. Isso se deve porque os defensores neoliberais pregavam, como única alternativa para sair da crise, a redução da intervenção estatal e a implementação do receituário neoliberal. Como exemplo de gestões governamentais neoliberais têm-se o governo de Margareth Thatcher (de 1979 a 1990) na Inglaterra, de Ronald Reagan (de 1981 a 1989) nos Estados Unidos e de Helmuth Kohl (de 1982 a 1998) na Alemanha.

0 regime neoliberal enfoca as relações contratuais de mercado e retoma muitos valores 
do liberalismo clássico do século XIX. De modo geral, o neoliberalismo determina: a não interferência do Estado, especialmente na economia, com a justificativa de que o mercado se autorregula; a privatização de empresas estatais; a reestruturação do aparato legal que regulamenta as relações de trabalho, tornando-as mais flexíveis para a contratação de mão de obra; o combate a políticas sociais ou redistributivas, pois são encaradas como onerosas; o ataque às pressões fiscais e regulamentações de contratos entre particulares; a transferência de ações sociais para empresas privadas ou organizações da sociedade civil; a diminuição das despesas públicas, entre outros (MORAES, 2001).

Prega-se o lema de Estado mínimo, porém sabe-se que, subjacente a este argumento, pretendem um Estado mínimo para os direitos sociais e trabalhistas, e máximo para o capital (NETTO; BRAZ, 2012). Harvey (2011, p. 32) ao ponderar criticamente as mazelas do neoliberalismo, também apresenta outras ações para a intervenção deste pensamento:

[...] enfrentar o poder sindical, atacar todas as formas de solidariedade social que prejudicassem a flexibilidade competitiva (como as expressas pela governança municipal e mesmo o poder de muitos profissionais e de suas associações), desmantelar ou reverter os compromissos do Estado de bem-estar social, privatizar empresas públicas (incluindo as dedicadas à moradia popular), reduzir impostos, promover a inciativa dos empreendedores e criar um clima de negócios favorável para induzi um forte fluxo de investimento externo (particularmente do Japão).

Por meio de um intenso processo de persuasão via produção de discursos, imagens e valores, o regime neoliberal difunde a ideia que se vive melhor em Estados neoliberais, com a liberdade instituída. O discurso neoliberal tornase hegemônico e atinge até mesmo os pensamentos e práticas cotidianas de pessoas. Conforme afirmam Robertson e Dale (2001), nasce uma nova identidade neoliberal, pautada em práticas sociais, emocionais e cognitivas relacionadas ao comportamento empreendedor, ao individualismo, ao cálculo do risco, a autorreflexão e a competitividade.

Entretanto, é preciso considerar a abissal desigualdade entre países, regiões e pessoas. Muitas destas são marginalizadas e excluídas da sociedade de regime neoliberal. Até mesmo os pensadores do neoliberalismo asseveram que nessa nova etapa do sistema capitalista não haverá lugar para todos.

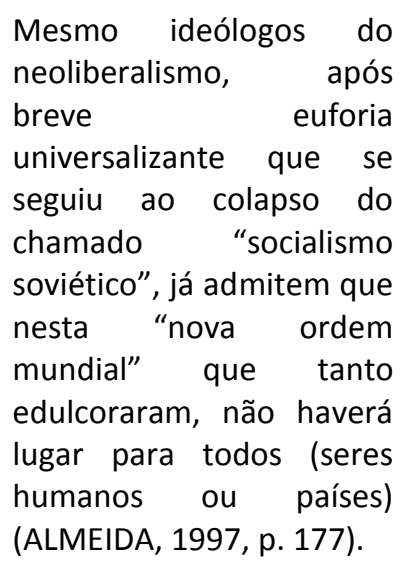

Para os neoliberais, as políticas sociais implementadas pelo Estado são uma espécie de faca de dois gumes. Por um lado, às ações públicas de caráter social são direcionadas para atender a população mais carente de recursos materiais, que necessitam dos subsídios do governo para conseguirem sobreviver em um mundo, no qual o sistema capitalista amplia a segregação social. Desta forma, tais atuações públicas servem como "política de pão e circo", os quais dão aos pobres o mínimo, para fazer com que estes não se rebelem contra o sistema. Por outro lado, as políticas sociais fazem-se "inimigas" do ideário neoliberal, pois para os seus defensores o mercado deve regular tudo, cabendo aos indivíduos à responsabilidade de se preparem o máximo possível para manter sua existência em uma sociedade que a competição é a válvula motora que permite a economia atingir elevados níveis de crescimento.

No decênio de 1980, alguns países que compõem a região da América Latina também viveram uma estagnação econômica marcada pela redução da produção das indústrias e do desenvolvimento econômico (NOMA, 2011). Sobre esse período Bresser-Pereira (1991, p. 3) afirma: 
A América Latina atravessa a pior crise de sua história - uma crise marcada por estagnação econômica e por altas taxas de inflação. Os desempenhos dos países não são, porém, uniformes, já que uns poucos estão crescendo e um número um pouco maior logrou uma relativa estabilidade de preços. $\mathrm{Na}$ média, todavia, prevalecem a paralisação senão o retrocesso da renda por habitante e taxas de inflação muito elevadas. Muitos destes países vivem, nos últimos anos, um processo de espiral inflacionária intermitente interrompido por congelamento de preços.

Como única alternativa para a superação da crise, o neoliberalismo também atingiu as políticas dos países da América Latina e Caribe. Consoante Krawczyk (2010, p. 10), “[...] a reforma do Estado - vetor das transformações educacionais - foi apresentada à sociedade como uma estratégia necessária para racionalizar os investimentos e a gestão pública e não como finalidade última do projeto de desenvolvimento neoliberal". Segundo Moraes (2001), nessa região os primeiros governos que acolheram as orientações neoliberais foram as ditaduras de Augusto Pinochet (de 1973 a 1990) no Chile e do general Jorge Rafael Videla (de 1976 a 1981) na Argentina. Além destes, países como Venezuela, Bolívia e Brasil também tiveram como imposições dos programas neoliberais.

No Brasil, o receituário neoliberal foi introduzido durante o governo de Fernando Collor de Mello (1990-1992), mas é no governo de Fernando Henrique Cardoso (1995-2002) que a premissas neoliberais foram instituídas por meio da Reforma do Aparelho do Estado, empreendida pelo Ministério da Administração Federal e Reforma do Estado (MARE). As mudanças provocadas por essa Reforma foram marcadas pela redefinição do papel do Estado, o que visou à diminuição das funções estatais, e pela adoção de um modelo de gestão pública gerencial na administração do Estado, dentre outras alterações. "A reforma do aparelho do
Estado foi ampla, abrangendo várias áreas do governo, a exemplo dos sistemas jurídico-legal, tributário e fiscal, previdenciário e econômico (CARVALHO, 2012, p. 217)".

A Reforma do Aparelho do Estado provocou também uma reforma da educação brasileira. Isso não aconteceu somente no Brasil, mas também nos demais países da América Latina e Caribe. Percebe-se que as políticas neoliberais não se restringem ao campo da economia e da política. Estas chegam às discussões relativas à educação e encaram o processo educativo sob a ótica mercadológica, fato que desencadeia em mudanças nas políticas e gestão educacional dos países.

\section{Implicações do Neoliberalismo no campo educacional}

Conforme as ideias neoliberais, a educação deixa de ser parte do campo social e político para fazer parte do mercado e funcionar conforme sua lógica. Marrach (1996) destaca que as práticas neoliberais contribuem para a organização estratégica da educação da seguinte forma:

1. Atrelar a educação escolar à preparação para o trabalho e a pesquisa acadêmica ao imperativo do mercado ou às necessidades da livre iniciativa. Assegurar que o mundo empresarial tem interesse na educação porque deseja uma força de trabalho qualificada, apta para a competição no mercado nacional e internacional. [...] 2 . Tornar a escola um meio de transmissão dos seus princípios doutrinários. $\mathrm{O}$ que está em questão é a adequação da escola à ideologia dominante. [...] 3. Fazer da escola um mercado para os produtos da indústria cultural e da informática, o que, aliás, é coerente com idéia de fazer a escola funcionar de forma semelhante ao mercado, mas é contraditório porque, enquanto, no discurso, os neoliberais condenam a participação direta do 
Estado no financiamento da educação, na prática, não hesitam em aproveitar os subsídios estatais para divulgar seus produtos didáticos $\mathrm{e}$ paradidáticos no mercado escolar (MARRACH, 1996, p. 46-48).

Desta maneira, o neoliberalismo entende a instituição escolar no campo do mercado e das técnicas de gerenciamento, por esta prática, os alunos e seus familiares são vistos como consumidores do produto chamado "escola". Neste contexto, os conteúdos políticos de cidadania são substituídos pelos "direitos do consumidor". Corroborando com Marrach (1996), Gentili (1996) também apresenta que sob a perspectiva do neoliberalismo, o sistema educacional enfrenta uma crise gerencial.

Nas críticas do neoliberalismo, os sistemas educacionais enfrentam uma profunda crise de eficiência, eficácia e produtividade, relaciona-se a isto a existência de mecanismos de exclusão e discriminação educacional. De acordo com os neoliberais, a responsabilização desta crise é do Estado que tem sido ineficiente na gerência das políticas públicas, conforme destaca o autor:

$$
\begin{aligned}
& \text { A educação funciona mal } \\
& \text { porque foi } \\
& \text { malcriadamente peneirada } \\
& \text { pela política, porque foi } \\
& \text { profundamente } \\
& \text { estatizada. A ausência de } \\
& \text { um verdadeiro mercado } \\
& \text { educacional permite } \\
& \text { compreender a crise de } \\
& \text { qualidade que invade as } \\
& \text { instituições escolares. } \\
& \text { Construir tal mercado, [...], } \\
& \text { constitui um dos grandes } \\
& \text { desafios que as políticas } \\
& \text { neoliberais assumirão no } \\
& \text { campo educacional } \\
& \text { (GENTILI, 1996, p.5). }
\end{aligned}
$$

As argumentações de maior flexibilidade e dinamismo confirmam o discurso neoliberal, pois, para os defensores destas ideias, somente $o$ mercado, por meio da competição e do mérito, baseado no esforço individual envolvidos no campo educacional, poderá promover os mecanismos que garantam eficiência e eficácia.

\begin{tabular}{|c|}
\hline $\begin{array}{l}\text { tornar a } \\
\text { educacional } \\
\text { com as } \\
\text { ninimização } \\
\text { lidades dos } \\
\text { nais. Nesta } \\
\text { organização } \\
\text { o sistema } \\
\text { da escola } \\
\text { dimensões } \\
\text { as reformas }\end{array}$ \\
\hline
\end{tabular}
Não existe mercado sem concorrência, e isso é um requisito para garantir o que os neoliberais denominam de equidade (GENTILI, 1996).

Tendo como base esses argumentos, muitas nações realizaram reformas educacionais para a superação da crise nesse campo. Nesta nova fase do capitalismo, a questão educacional é considerada um fator essencial na competitividade entre as nações (NASCIMENTO, 2007).

Na América Latina e no Brasil, a reforma odo Estado correu não apenas pautada nos interesses neoliberais, mas também foi impulsionada pelas orientações de Organizações e Organismos Internacionais que influenciam nas agendas políticas nacionais.

Para clarificar como ocorre a atuação das OOs nas políticas educacionais dos Estados, a seguir, apresentam-se alguns elementos dessas interferências que contribuíram no desenvolvimento de reformas educacionais e que conduziram as nações a seguirem objetivos de projetos educacionais, como o PPE que será explicado no quarto item deste artigo. 
3. Interferências de Organizações e Organismos Internacionais nas agendas políticas educacionais

No item anterior já foi mencionado que as Organizações e Organismos internacionais (OOs) foram criados a partir de 1944 por meio dos acordos de Bretton Woods. Neste item busca-se elucidar, sinteticamente, as influências da atuação das OOs nas agendas políticas dos países, especialmente na área educacional.

Apesar de as OOs serem criadas após a Segunda Guerra Mundial, é na década de 1990 que se observam suas acentuadas articulações junto aos países. Isso foi proporcionado devido a Doutrina Neoliberal adotada pelos governantes de alguns Estados e, sobretudo, por meio do processo de globalização que atingiu os aspectos econômicos, políticos, sociais e culturais das nações a partir da década de 1980. A globalização, caracterizada pela interação entre países e pessoas, consiste na interligação política, econômica, social e cultural. Na definição desse conceito, Olsson (2001, p.79) oferece importantes elementos:

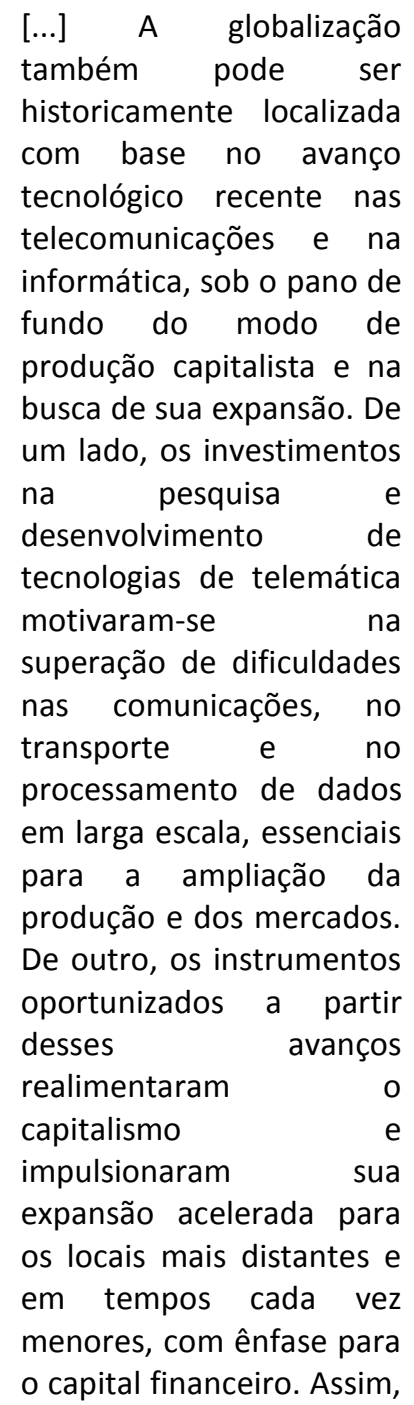

estabelece-se um termo inicial relativamente recente para o processo de globalização, pelo menos na acepção que aqui se emprega para o exame dos novos papéis e cenários dos atores internacionais.

Esta nova etapa do capitalismo, que recebeu o nome de Globalização, de mundialização e de transnacionalização, possibilitou, além da expansão do neoliberalismo em nível mundial, a realização de acordos entre os países, como a constituição de blocos econômicos, em busca de novos mercados consumidores e a reestruturação do sistema capitalista. Ainda, esse processo de mundialização viabilizou e viabiliza a atuação das OOs nas agendas políticas nacionais.

As recomendações das OOs são intensamente disseminadas pelas reuniões internacionais, publicações de documentos, relatórios, assessorias, seminários, portais da internet e diversas mídias, dentre outros canais de divulgação (ROSEMBERG, 2000). Silveira (1999) destaca que as reuniões e as Conferências Internacionais de Educação (CIEs) são espaços de divulgação e de articulação das relações de poder entre as nações acerca das diretrizes políticas.

As temáticas contidas nesses canais de divulgação, especialmente aquelas debatidas nas Conferências Internacionais não são neutras, mas demonstram intencionalidades a serem atendidas. Embora estas discussões não incidam diretamente e imediatamente nas diretrizes políticas locais, na maioria das vezes, os países acatam as recomendações das OOs e elaboram programas e projetos sociais para atender as orientações internacionais.

Assim, o estabelecimento
de uma posição de
consenso $\begin{array}{r}\text { internacional } \\ \text { sobre determinados }\end{array}$
temas, tendo como
legitimador de tais
posições, os organismos
internacionais, conferiu ao
Estado, em especial os
mais pobres, função de
executor de programas e
medidas de origem
transnacional rara
salvaguardar a macro-
economia e assegurar o


desenvolvimento dentro do modelo capitalista. A educação nesse sentido foi, e ainda é caracterizada como fator de redução de desigualdades e como elemento de desenvolvimento social dentro do conceito democrático de Estado (BENDRATH; GOMES, 2010, p. 160).

Ainda que existam proposições de OOs, é preciso destacar que não há uma vitimização dos países diante das recomendações internacionais. Nesse processo existem os interesses nacionais dos países que decidem incluir ou não determinada política mundial em sua agenda local. Consoante Dale (2010), os Estados-nação estão longe de serem vítimas indefesas, estes são agentes conscientes e, muitas vezes, parceiros na relação com outros agentes da globalização. Por sua vez, Rosemberg (2000, p. 64) sinaliza:

[...] deve-se atentar para não se cair em falácias habituais: de se considerar que as orientações políticas das OMs são impostas aos governos nacionais sem sua anuência; de que as OMs sejam instituições homogêneas e que suas orientações sejam formuladas em base perfeitamente harmônica.

Uma das áreas mais atingidas pelas recomendações das OOs é a educação. A agência especializada do Sistema da Organização das Nações Unidas que se detinha a esta área, em nível mundial, era a UNESCO ${ }^{4}$. Contudo, a partir da década de 1990 outras organizações conseguiram espaço nas discussões sobre políticas educacionais ${ }^{5}$.

\footnotetext{
${ }^{4}$ A criação da UNESCO data-se de 16 de novembro de 1945 . Esta é uma agência da ONU que atua não apenas na área de educação, mas também nas Ciências Naturais, Ciências Humanas e Sociais, na Cultura e Comunicação, bem como na Informação. A UNESCO realiza projetos de cooperação técnica junto aos governos dos países, a sociedade civil e ao setor privado. Além do mais, colabora na elaboração de políticas que estão em consonância com as metas assumidas por seus Estados-membros.

${ }^{5}$ Outros Organismos e Organizações passaram a deliberar sobre a educação dos países, como o Banco Mundial (BM) e a Organização para a Cooperação e Desenvolvimento Econômico (OCDE).
}

Na década de 1990, as orientações das OOs impulsionaram diferentes reformas educacionais aos países da América Latina e Caribe.

$\mathrm{Na}$ última década do século 20, quase todos os países da América Latina e do Caribe iniciaram reformas educacionais resultantes em grande medida de um processo de indução externa liderado pelos organismos internacionais principalmente o Banco Mundial e o Banco Interamericano de Desenvolvimento - que condicionavam a concessão de empréstimos aos Estados nacionais da região à implantação dessas reformas (KRAWCZYK, 2010, p. 10).

Dentre as principais mudanças propostas na educação, sinteticamente, tem-se: a descentralização/centralização da educação, que proporcionou 0 repasse de determinadas responsabilidades, antes do governo central, aos estados e municípios, porém é preciso lembrar que o planejamento e a avaliação ficam a cargo do governo nacional; ênfase no desenvolvimento da autonomia financeira e pedagógica das escolas, para que essas consigam administrar e sustentar-se com recursos próprios, convidando a comunidade a integrar serviços escolares; elaborações de programas e ações educativas com foco no ensino básico; desenvolvimento de sistemas nacionais para aferição dos níveis educacionais, por meio da criação de avaliações de diferentes etapas educativas; aproximação o setor público com o setor privado, que se deu pela participação de agentes privados nas deliberações e ações anteriormente públicas (GAJARDO, 2000). Nesse aspecto, Trojan resume (2010, p. 56):

Na educação, a reforma do Estado e a redução dos gastos públicos com políticas sociais causaram impactos na gestão do sistema na maioria dos países latino-americanos, destacando-se 
municipalização da educação obrigatória, mudanças no modelo de gestão e a instituição de sistemas nacionais de avaliação.

Estas transformações foram respaldadas pela alteração e elaboração de legislações educacionais, que interferirem no planejamento, na gestão, no financiamento e nos currículos escolares das nações da região (NOMA, 2011).

Para demonstrar a materialização das interferências das OOs, em específico da UNESCO, e das ideias neoliberais nas políticas educacionais dessa região, apresenta-se, no próximo item, o Projeto Principal de Educação para a América Latina e Caribe (PPE) elaborado pela Organização das Nações Unidas para a Educação, a Ciência e a Cultura (UNESCO). Optouse por exibir o PPE porque este, nas duas últimas décadas do século $X X$, assumiu função importante na definição de diretrizes políticas dos países da América Latina e Caribe.

\section{As diretrizes políticas do Projeto Principal de Educação para a América Latina e o Caribe}

A origem do Projeto Principal de Educação para a América Latina e Caribe (PPE) surgiu no ano de 1979, na Cidade do México, na denominada Conferência Regional de Ministros da Educação e Ministros Encarregados do Planejamento Econômico dos Estados membros da América Latina e Caribe. Esta conferência foi organizada pela UNESCO com a colaboração da CEPAL e da Organização dos Estados Americanos (OEA). Nesta foram colocadas à tona as prioridades das políticas voltadas para encarar as dificuldades educacionais identificadas na década de 1970. Para concretizar a superação destas dificuldades, os representantes dos países que participaram da reunião, signatários da Declaración de Ciudad de México (1979), documento aprovado por meio dessa conferência, solicitaram a UNESCO que elaborasse um Projeto Principal que contemplasse os objetivos elencados na Declaração.

Em 1981, foi realizada uma reunião regional, na cidade de Quito, Equador, na qual a UNESCO apresentou os objetivos, as modalidades e as estratégias de ação do PPE. Estas metas foram aprovadas pelos representantes dos
Estados-membros e foram instituídas na Recomendación de Quito, documento que abarca os objetivos estabelecidos do PPE (NOMA, 2011).

O Projeto Principal para a América Latina e Caribe foi coordenado pelo Escritório Regional de Educação para a América Latina e o Caribe, mais conhecido pela sua nomenclatura em espanhol Oficina Regional de Educación para América Latina y el Caribe (OREALC) ${ }^{6}$ e perdurou de 1980 até o ano 2000. Durante os 20 anos de vigência do Projeto, foram realizadas diversas reuniões do Comitê Regional Intergovernamental do Projeto Principal de Educação para a América Latina e Caribe (Promedlac), com a participação dos Ministros de Educação dos Estados Membros e representantes oficiais. As reuniões do Promedlac foram: Cidade do México (1984), Bogotá (1987), Guatemala (1989), Quito (1991), Santiago (1993), Kingston (1996) e Cochabamba (2001).

O PPE tinha o intuito de melhorar a escolaridade da população dos países membros e buscou articular a educação e cultura, a educação e trabalho, a educação formal e não formal (UNESCO, 1998). Os três objetivos do PPE foram:

1) Garantir e oferecer, até o final de 1999, uma educação geral mínima de 8 a 10 anos a todas as crianças em idade escolar; 2) Eliminar 0 analfabetismo até o final do século e desenvolver e ampliar os serviços educacionais para adultos; 3) Melhorar a qualidade e a eficiência dos sistemas educacionais por meio das reformas necessárias; (UNESCO, 1998, p.23).

Para os países envolvidos, o PPE significou $O$ início do desenvolvimento educacional na década de 1980 , priorizou a expansão da educação à maioria da população e enfatizou $o$ atendimento dos grupos mais desfavorecidos e vulneráveis: "[...] analfabetos de 15 anos ou mais, jovens e crianças do meio rural, menores de 6 anos em situações desfavoráveis e

\footnotetext{
${ }^{6}$ A OREALC subordina-se a UNESCO e seu escritório localiza-se, desde 1969, na cidade de Santiago, no Chile. Segundo Noma (2011), a OREALC ampara os países da região na elaboração de estratégias para as políticas educacionais e tem função de mobilizar os países acerca dos temas das Conferências Internacionais.
} 
crianças com necessidades especiais de aprendizagem" (UNESCO, 1998, p. 23).

Quadro 1. Reuniões do Promedlac

\begin{tabular}{|c|c|c|}
\hline REUNIÃO & LOCAL E DATA & OBJETIVOS/COMPROMISSOS \\
\hline $\begin{array}{c}\text { PROMEDLAC } \\
\text { I }\end{array}$ & $\begin{array}{l}\text { Cidade do } \\
\text { México, 1984. }\end{array}$ & $\begin{array}{l}\text { - Garantir a escolaridade para crianças e jovens e oferecer uma educação básica } \\
\text { mínima de } 8 \text { a } 10 \text { anos; } \\
\text { - Eliminar o analfabetismo e expandir os serviços educacionais para os adultos; } \\
\text { - Melhorar a qualidade e a eficiência da educação. }\end{array}$ \\
\hline $\begin{array}{c}\text { PROMEDLAC } \\
\text { II }\end{array}$ & Bogotá, 1987. & Foram reforçados os compromissos acordados na primeira reunião. \\
\hline $\begin{array}{c}\text { PROMEDLAC } \\
\text { III }\end{array}$ & $\begin{array}{l}\text { Guatemala, } \\
1989 .\end{array}$ & $\begin{array}{l}\text { - Aumentar a eficácia e a eficiência dos sistemas educacionais; } \\
\text { - Aumentar os níveis de responsabilidade pelos resultados; } \\
\text { - Articular corretamente as ações do Estado entre os níveis central, regional e } \\
\text { nacional. }\end{array}$ \\
\hline $\begin{array}{c}\text { PROMEDLAC } \\
\text { IV }\end{array}$ & Quito, 1991. & $\begin{array}{l}\text { - Transformar o modelo de gestão educacional que permita a articulação com } \\
\text { demandas econômicas, sociais, políticas e culturais; } \\
\text { - Promover processos de descentralização e regionalização; } \\
\text { - Criar mecanismos ágeis para a avaliação de resultados; } \\
\text { - Implementar programas eficazes de compreensão educacional; } \\
\text { - Promover processos de profissionalização de professores; } \\
\text { - Promover a transformação do currículo baseada na satisfação das necessidades } \\
\text { educacionais básicas do indivíduo e da sociedade. }\end{array}$ \\
\hline $\begin{array}{c}\text { PROMEDLAC } \\
\mathrm{V}\end{array}$ & Santiago, 1993. & $\begin{array}{l}\text {-Objetivo geral: melhorar os níveis de qualidade de aprendizagem; } \\
\text { - Objetivos específicos: Elevar a quantidade e a qualidade de aprendizagem dos } \\
\text { alunos; } \\
\text { - Promover ações para reduzir as desigualdades de acordo com o critério da } \\
\text { discriminação positiva; }\end{array}$ \\
\hline $\begin{array}{c}\text { PROMEDLAC } \\
\text { VI }\end{array}$ & Kingston, 1996. & $\begin{array}{l}\text { - Garantir a participação da sociedade civil no desenvolvimento de políticas } \\
\text { públicas; } \\
\text { - Melhorar a capacidade de gestão, de forma a ter maior participação da } \\
\text { comunidade escolar e um papel mais estratégico da administração central; } \\
\text { - Universalizar a educação básica e a alfabetização funcional } \\
\text { (Estes objetivos firmados tiveram relação com o Relatório Jacque Delors - } \\
\text { UNESCO). }\end{array}$ \\
\hline $\begin{array}{c}\text { PROMEDLAC } \\
\text { VII }\end{array}$ & $\begin{array}{l}\text { Cochabamba, } \\
2001\end{array}$ & $\begin{array}{l}\text { Foram declaradas } 54 \text { recomendações, dentre as quais, pode-se citar: } \\
\text { - Desenvolver políticas nacionais abrangentes em relação a profissão docente; } \\
\text { - Formular estratégias para garantir que as escolas desenvolvam suas atividades } \\
\text { com autonomia pedagógica e de gestão necessárias para favorecer o trabalho dos } \\
\text { professores com os alunos. }\end{array}$ \\
\hline
\end{tabular}

Fonte: UNESCO, Declaraciones y

<http://www.unesco.org/new/es/santiago/previous-international-agenda/the-major-project-of-education-1980-

$2000 />$.

Apesar dos esforços empreendidos pelos países da América Latina e do Caribe, em relação a ampliação dos ano mínimos de escolaridade, fato que logrou êxito ainda é possível verificar que o analfabetismo é uma realidade existente, sobretudo nos países em desenvolvimento, caso do Brasil'. As sete reuniões do Promedlac, promovidas pela UNESCO, foram eventos importantes no que concerne ao

\footnotetext{
${ }^{7}$ De acordo com o Instituto Brasileiro de Geografia e Estatística (IBGE), por meio da Pesquisa Nacional por Amostra de Domicílios Contínua (PNAD Contínua), 7,2\% dos brasileiros se encontram na situação de analfabetismo, o que corresponde a 11,8 milhões de analfabetos.
}

desenvolvimento da educação, pois os chefes de Estado mostraram preocupações em melhorarem $\mathrm{o}$ atendimento e funcionamento dos sistemas e das instituições escolares, seja no aspecto quantitativo ou qualitativo.

Todavia, nem todos os objetivos foram alcançados. Atualmente na região da América Latina e Caribe ainda existem um grande contingente de pessoas que se encontram em situação de pobreza e o analfabetismo atinge milhões de sujeitos. Isso é constatado pela própria UNESCO, no âmbito da OREALC:

O começo do novo século encontra a América Latina 
e o Caribe com dois problemas preocupantes: os níveis de desigualdade mais altos do mundo e um grau elevado de vulnerabilidade das instituições mais importantes. Os prognósticos otimistas sobre a situação econômica não se realizaram. Os níveis de pobreza (211 milhões de pessoas) e de indigência (80 milhões) do final dos anos 90 mostraram sinais de agravamento. Aumentaram as disparidades entre países e no interior de cada país. A pobreza e a desigualdade mostraram seu rosto mais desumano na distribuição da riqueza. A renda dos $10 \%$ mais ricos supera, em muitos países, em até 20 vezes a renda dos $40 \%$ mais pobres. Cerca de $70 \%$ dos habitantes da região reside em domicílios com uma renda inferior à média. As políticas sociais não cumpriram o papel redistribuidor que se esperava delas (OREALC/UNESCO, 2004, p.7).

A situação de desemprego e subemprego são causas mais visíveis da pobreza e da exclusão. As pessoas mais afetadas continuam sendo os indígenas, as mulheres, os jovens e as pessoas de baixa renda (OREALC/UNESCO, 2004).

Como alternativa para concretizar os objetivos traçados no PPE, mas que não foram efetivados no período estipulado, foi elaborada outra ação com caráter de continuação do referido projeto: a criação de um segundo projeto pautado nas discussões da última Conferência do PPE, na Bolívia, em 2001. Este perduraria por 15 anos com avaliações a cada cinco anos durante sua vigência (COMAR, 2015).

Nesse sentido, em novembro de 2002, na reunião de Havana, Cuba, representantes de 34 países da região presentes aprovaram o Projeto Regional de Educação para América Latina e o
Caribe (PRELAC) e seu Modelo de Acompanhamento, para o período 2002-2017 (NOMA, 2011). Conforme o documento intitulado PRELAC, uma trajetória para a educação para todos, este novo projeto "[...] constitui um apoio aos planos de ação da Educação para Todos adotados no Fórum Mundial de Dakar (2000) e na Reunião Regional preparatória de Santo Domingo (OREALC/UNESCO, 2004, p. 7)".

Em breves palavras, o objetivo principal do PRELAC era promover transformações nas políticas e nas práticas educacionais, atuando na mobilização e articulação da cooperação dentro e entre os países para alcanças os propósitos firmados em Dakar (2000-2015). Além disso, outro objetivo do projeto era configurar-se como um fórum técnico e político na promoção do diálogo e de construção de alternativas entre toda a sociedade, bem como inspirar políticas educacionais inovadoras (OREALC/UNESCO, 2004).

Para tanto, o PRELAC estabeleceu cinco áreas como focos estratégicos, enfoca-se: nos conteúdos e práticas da educação; nos docentes e no fortalecimento de sua importância na mudança educacional; na cultura das escolas para que estas se convertam em comunidades de aprendizagem e participação; na gestão e na flexibilização dos sistemas educativos; na responsabilidade social pela educação para gerar compromissos com seu desenvolvimento e resultados (OREALC/UNESCO, 2004).

Considera-se que embora existam ações para melhorar os níveis de educação dos países da América Latina e Caribe, como o PPE, as questões educacionais sofrem muitas interferências da situação econômica dessa região. Esta última, em muitos casos, se sobrepõe as metas firmadas no âmbito da educação. Por isso, faz-se necessário, além de compreender as metas educativas, entender as influências do ideário e das práticas neoliberais, que embasam as ações políticas no contexto de reformas dos países latino americanos e caribenhos.

Ademais, ao versar sobre a educação de uma vasta região, como é o caso da América Latina e Caribe, é preciso considerar as diferenças existentes entre os países que compõem a referida região. Krawczyk (2010, p. 14) evidencia: As recomendações, os
empréstimos e a
transposição de conceitos
e políticas e soluções
educacionais, em escala 
regional e internacional, condicionaram as políticas educacionais nacionais, mas a dinâmica histórica e a conjuntura de cada um dos países deram à Reforma Educacional uma concretização diferente.

Apesar das semelhanças dos problemas enfrentados É necessário romper com o pressuposto de homogeneização de muitas OOs que elaboram projetos educacionais para os países desconsiderando suas diferenças históricas, econômicas políticas e culturais que interferem na concretização das metas educacionais estipuladas em âmbito internacional.

\section{CONCLUSÕES}

A educação é alvo importante no contexto das políticas mundiais e sua agenda política recebe influências das Organizações e Organismos internacionais. As OOs formulam propostas, fóruns, projetos, boletins, recomendações, acordos, tratados, além de auxílio técnico e financeiro. Diversos projetos e programas foram desenvolvidos no mundo nas últimas três décadas pelos organismos internacionais, com os mais diversos objetivos, entre eles: erradicar o analfabetismo; melhorar a qualidade dos sistemas educativos; fazer da escola uma fonte de qualificação do trabalhador em um cenário cada vez mais competitivo no mercado de trabalho, entre outras metas. O papel desempenhado pelas OOs ultrapassa a concessão de crédito, passando a influenciar as reformas estruturais e as políticas internas dos países, especialmente por meio de estratégias que envolvem o estabelecimento de précondições necessárias para a aprovação de recursos a serem investidos.

Todavia, é importante salientar que a definição de uma agenda política mundial de educação não é definida somente por cópia dos modelos e diretrizes que são propalados pelos OOs. Nesse sentido, cabe avaliar que determinações da política educacional aos países da América Latina e Caribe também são definidas por mecanismos de regulamento nacional e local, mediante características sociais, culturais e econômicas particulares do contexto nacional em que foram produzidos.
As políticas de educação implementadas no Brasil são resultados das transformações decorrentes dos processos de reestruturação e manutenção do sistema capitalista mundial, consequência da internacionalização e globalização da economia e da utilização de medidas de ajustamento econômico e político de cunho neoliberal. Essas mudanças privilegiaram as relações de mercado em detrimento da vida social e da satisfação das necessidades básicas de parte da população, como educação, saúde, transporte, entre outros, ocorrentes da minimização do papel do Estado em suas funções de promoção e garantia da equidade social.

Faz-se necessário analisar historicamente e criticamente as definições da política educacional, por meio de programas e projetos a fim de se ter uma visão que não se restrinja somente ao local ou somente ao contexto internacional e teórico, porque todas essas relações, imbuídas de intencionalidade, interferem diretamente ou indiretamente, no processo de definição das políticas educacionais.

\section{REFERÊNCIAS}

ALMEIDA, Lúcio Flávio de. Entre o local e o global: poder e política na atual fase de transnacionalização do capitalismo. In: DOWBOR, Ladislau; IANNI, Octavio; RESENDE, Paulo-Edgar A. Desafios da globalização. Petrópolis (RJ): Vozes, 1997. p. 175-186.

BARRETO, Pedro Henrique. História - Bretton Woods. Revista Desafios do Desenvolvimento, Brasília, ano 6, n. 50, maio. 2009. Disponível em: http://desafios.ipea.gov.br/index.php?option=co

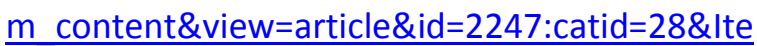
$\underline{\mathrm{mid}=23}$. . Acesso em: 23 de dez. 2017.

BENDRATH, Eduard Angelo; GOMES, Alberto Albuquerque. Estado, políticas públicas e organismos internacionais: a educação no foco do debate. InterMeio, Campo Grande, v.16, n.32, p. 157-171, jul./dez. 2010.

CARVALHO, Elma Júlia Gonçalves de. Políticas públicas e gestão da educação no Brasil. Maringá, EDUEM, 2012.

COMAR, Sueli Ribeiro. A repercussão do Projeto Principal de Educação nas políticas brasileiras para avaliação em larga escala. In: Seminário Nacional Interdisciplinar em experiências educativas, 5., 2015, Francisco Beltrão. Anais... 
Francisco Beltrão: Unioeste, 2015. Disponível em: http://cacphp.unioeste.br/eventos/senieeseminario/anais/ Eixo6/A REPERCUSSAO DO PROJETO PRINCIPAL DE EDUCACAO NAS POLITICAS BRASILEIRAS P ARA AVALIACAO EM LARGA ESCALA.pdf.

Acesso em: 21 de jan. de 2018.

DALE, Roger. A sociologia da educação e o Estado após a globalização. Educação \& Sociedade, Campinas, v. 31 , n. 113 , p. $1099-1120$, out../dez. 2010. https://doi.org/10.1590/S010173302010000400003

GAJARDO, Marcela. Reformas educativas na América Latina: balanço de uma década. Programa de Promoção da Reforma Educativa na América Latina e Caribe, 2000. Disponível em: http://www.oei.es/reformaseducativas/reformas educativas AL balance gajardo portugues.pdf. Acesso em 22 de jan. 2018.

GENTILI, Pablo. Neoliberalismo e educação: manual do usuário. In: SILVA, T. T. da; GENTILI, P. (Orgs.). Escola S.A.: quem ganha e quem perde no mercado educacional do neoliberalismo. Brasília, DF: CNTE, 1996, p. 1-16.

HARVEY, David. O Neoliberalismo: história e implicações. 2. ed. São Paulo: Edições Loyola, 2011.

KRAWCZYK, Nora Rut. A reforma educacional na América Latina nos anos 90. Uma perspectiva histórico-sociológica. Revista Latinoamericana de Educación Comparada, Buenos Aires (ARG), n. 1, p. 10-17, 2010.

MARRACH, S. A. Neoliberalismo e Educação. In: GUIRALDELLI JUNIOR, P. (Org.). Infância, Educação e Neoliberalismo. São Paulo: Cortez, 1996. p. 42-56.

MORAES, Reginaldo C. Neoliberalismo: de onde vem para onde vai? São Paulo: Senac, 2001.

MOREIRA, Jani Alves da Silva. Políticas de financiamento e gestão da educação básica (1990-2010): os casos de Brasil e Portugal. Maringá $\quad(P R): \quad$ Eduem, 2015. https://doi.org/10.7476/9788576286547

NASCIMENTO, M. N.M. Ensino médio no Brasil: determinações históricas. Publ. UEPG Ci. Hum.,
Ci. Soc. Apl., Ling., Letras e Artes, Ponta Grossa, v. 15 , n. 1, p. 77-87, jun. 2007. Disponível em: www.revistas2.uepg.br/index.php/sociais/article/ download/2812/2097. Acesso em: 26 jul. 2017.

NOMA, Amélia Kimiko. História das políticas educacionais para a América Latina e o Caribe: o projeto principal de educação (1980-2000). In: AZEVEDO, Mário Luiz Neves; LARA, Ângela Mara de Barros. Políticas para a educação: análises e apontamentos, 2011. p. 105-133.

NETTO, José Paulo; BRAZ, Marcelo. Economia Política: uma introdução crítica. São Paulo: Cortez, 2012.

OLSSON, Giovanni. O fenômeno da globalização e o novo cenário dos atores das relações internacionais. Florianópolis: UFSC, 2001. 191 f. Dissertação (Mestrado em Direito), PósGraduação em Direito, Universidade Federal de Santa Catarina, Florianópolis, 2001.

ORGANIZAÇÃO DAS NACÕES UNIDAS NO BRASIL. UNESCO, 2018. Disponível em: https://nacoesunidas.org/agencia/unesco/.

Acesso em: 22 de jan. de 2018.

OREALC/UNESCO. PRELAC. Uma trajetória para a educação para todos. Revista PRELAC, Santiago do Chile, Ano 1, n.0, agosto de 2004. Disponível em:

http://unesdoc.unesco.org/images/0013/00137/ 137293por.pdf. Acesso em: 11 jul. 2017.

ROBERTSON, Susan; DALE, Roger. Regulação e risco na governação da educação. Gestão dos problemas de legitimação e coesão social em educação nos Estados competitivos. Educação, Sociedade e Culturas, Porto (PT), n. 15, p. 117147, 2001.

ROSEMBERG, Fúlvia. Uma introdução ao estudo das organizações multilaterais no campo educacional. In: KRAWCZYK, Nora; CAMPOS, Maria Malta; HADDAD, Sérgio (orgs). 0 cenário educacional latino-americano no limiar do século XXI: reformas em debate. Campinas: Autores Associados, 2000. p. 63-92.

UNESCO. A Unesco e a educação na América Latina e Caribe (1987-1997). Santiago-Chile, 1998. 
UNESCO. Recomendación de Ciudad de México.

$1985 . \quad$ Disponível em:

http://unesdoc.unesco.org/images/0014/001468

/146844s.pdf. Acesso em: 30 out. 2017.

UNESCO. Recomendaciones de Bogotá sobre prioridades de acción para el período 1987-1989 en el marco del Proyecto Principal. 1987. Disponível em: http://unesdoc.unesco.org/images/0014/001468 /146859s.pdf. Acesso em: 30 out. 2017.

UNESCO. Recomendación de Guatemala relativa al Segundo Plan Regional de Acción del Proyecto Principal de Educación en América Latina y el Caribe. 1989. Disponível em: http://unesdoc.unesco.org/images/0008/000839 083983 s.pdf. Acesso em: 30 out. 2017.

UNESCO. Recomendación de Quito a la ejecución de los Planes Nacionales de Acción del PPE (1990-1995). 1991. Disponível em: unesdoc.unesco.org/images/0009/000905/09051 5s.pdf. Acesso em: 30 out. 2017.

UNESCO. Recomendación de Santiago para la ejecución del Proyecto Principal de Educación en el período 1993-1996. 1993. Disponível em: http://unesdoc.unesco.org/images/0009/000952 095252s.pdf. Acesso em: 30 out. 2017.

UNESCO. Recomendación de Kingston: Educación, Democracia, Paz y Desarrollo. 1996. Disponível em: http://unesdoc.unesco.org/images/0010/001047 /104761s.pdf\#104761. Acesso em: 30 out. 2017.

UNESCO. Declaración de Cochabamba y Recomendaciones sobre Políticas Educativas al Inicio del Siglo XXI. 2001. Disponível em: http://unesdoc.unesco.org/images/0012/001214 L121485s.pdf. Acesso em: 30 out. 2017.

UNESCO. Declaraciones y Recomendaciones, $2017 . \quad$ Disponível em: http://www.unesco.org/new/es/santiago/previo us-international-agenda/the-major-project-ofeducation-1980-2000/. Acesso em: 30 out. 2017.

Recebido para publicação em: 03/11/2017

Revisado em: 30/01/2018

Aceito em: 09/03/2018 